\title{
Vehicle Insurance Model Using Telematics System with Improved Machine Learning Techniques: A Survey
}

\author{
Theyyagura Mani Kanta Reddy ${ }^{1 *}$, Bulla Premamayudu ${ }^{2}$ \\ ${ }^{1}$ Department of IT, VFSTR Deemed to be University, Vadlamudi, Guntur 522017, Andhra Pradesh, India \\ ${ }^{2}$ VFSTR Deemed to be University, Vadlamudi, Guntur 522017, Andhra Pradesh, India
}

Corresponding Author Email: manikantareddy.t@gmail.com

https://doi.org/10.18280/isi.240507

Received: 23 May 2019

Accepted: 8 August 2019

\section{Keywords:}

motor insurance, premium calculation, drivers driving conduct, block chain, machine learning approach

\begin{abstract}
In the field of vehicle insurance, the current models for premium calculation and charging are not friendly to end users. Many important parameters are not considered in these models, such as mileage, driving conduct and road type. This paper designs a vehicle insurance model based on telematics system and machine learning. With telematics system as the foundation, the key of the model construction is to select a suitable algorithm to assess the driving style of the driver, which is an important influencing factor of the car crash likelihood. Deep learning techniques like artificial neural network (ANN), Bayesian network and fuzzy logic were examined, and combined with block chain technology to improve the premium calculation based on driving style. The effectiveness of the established model was fully analyzed, providing a novel angle to premium calculation of vehicle insurance.
\end{abstract}

\section{INTRODUCTION}

Driving-and road security are present and developing issues with worldwide measurements. As per the worldwide status report on road security held by the World Health Organization [1] (WHO) in 2017, 1.74 million traffic-related accidents happen every year around the world, as of now the main source of death for individuals matured 15-29 years [2].

Because of the expanded requirement for versatility in creating nations the constant development of vehicle producing is clear [3]. The advancement of the worldwide vehicle division causes a framework excess, which thusly is in charge of expanded traffic dangers and accident commonness [4]. The telematics process is depicted in Figure 1.

Also, contextualization of the received telematics information is huge part of guaranteeing as exact and solid information for conveying altered arrangements. The setting alludes to the natural factors, for example, area where certain occasions happened, conditions out and about, climate conditions, and their general commitment to accident. The natural factor has been distinguished as central for the most recent UBI period and better understandings of driver's conduct.

Insurance agencies have begun giving protection strategies which include an incentive to clients based on utilization of vehicles [5]. Pay how you drive (PAYHD) and Pay as you drive (PAYD) protection approaches measure driving conduct notwithstanding separation expedition. The attention as far as kind of use is more in PAYHD [6] contrasted with PAYD [7]. Telematics give leverage to the client by giving prompt criticism circle to the driver with respect to the danger included and the dynamic expense of the protection [8]. So it goes about as an impediment to the driver to control from neglectful driving quickly for security of self, co-travelers and people on foot.
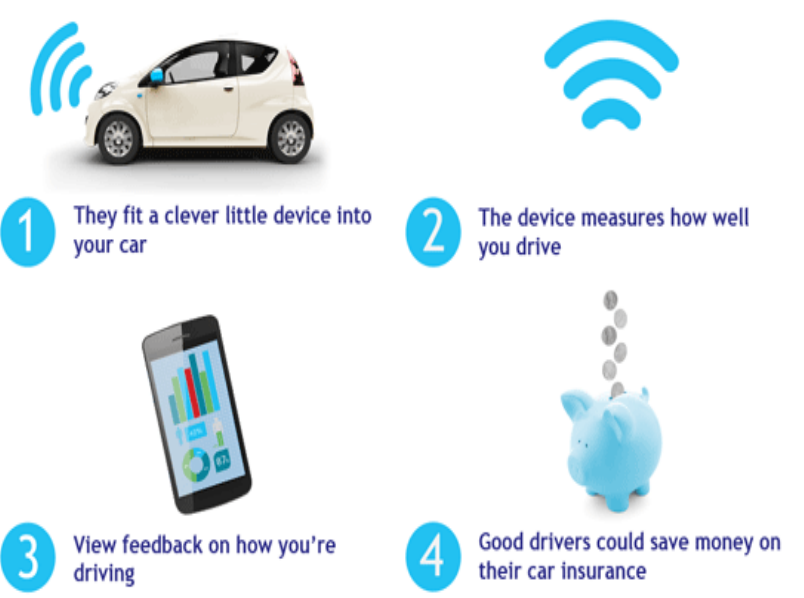

View feedback on how you're driving

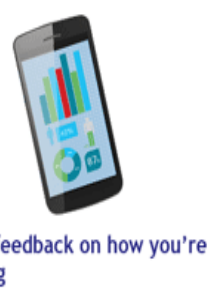

their car insurance

\subsection{Significance of telematics-based protection}

Protection industry, in any event with regards to engine protection, achieved its development lifecycle organization [9] Particularly with regards to markets, where Motor Insurance is the most essential piece of the item portfolio, this forces critical accident for business manageability [10].

Insurance agencies may endure loss of income, essentially due to two reasons. Right off the bat, the costs on these business sectors are probably going to dive [11]. Besides, valuing isn't steady with individual accident [12]. For instance, there are individuals who drive $35.000 \mathrm{Km}$ every year and pay a similar value like individuals who drive under 10.000 every year. This has prompted an adjustment in the worldview of conventional protection approaches by offering new use based protection (UBI) strategies [13]. 
UBI depends on a heap of information, for example, mileage, speed, area, time, complete term of excursion and so on extrapolated from telematics gadgets. This information can be prescient and organizations could increase upper hand by dissecting drivers' conduct [14]. UBI items are still new on certain business sectors, and to acquaint it with their separate markets, insurance agencies should put a ton of exertion to build the reception of UBI [15].

\subsection{Significance of telematics information}

Telematics information is utilized to decide the policyholder's vehicle protection premium [16]. Insurance agencies require more extravagant information to evaluate chance all the more unequivocally and comprehend driver's conduct [17]. It's imperative for insurance agencies to separate this information and that their UBI frameworks that gather the privilege telematics parameters. Furthermore, this could permit insurance agencies to improve their charging strategies by adjusting singular cost all the more unequivocally.

Protection telematics relies upon the exactness of the GPS (Global Positioning System) information from the telematics gadget. Different ecological factors, for example, barometrical impacts, weather conditions, and so on may cause a specific clamor in the exactness and unwavering quality of GPS information [18]. This could cause pertinent income trouble accident to insurance agency. The telematics information usage is depicted in Figure 2.

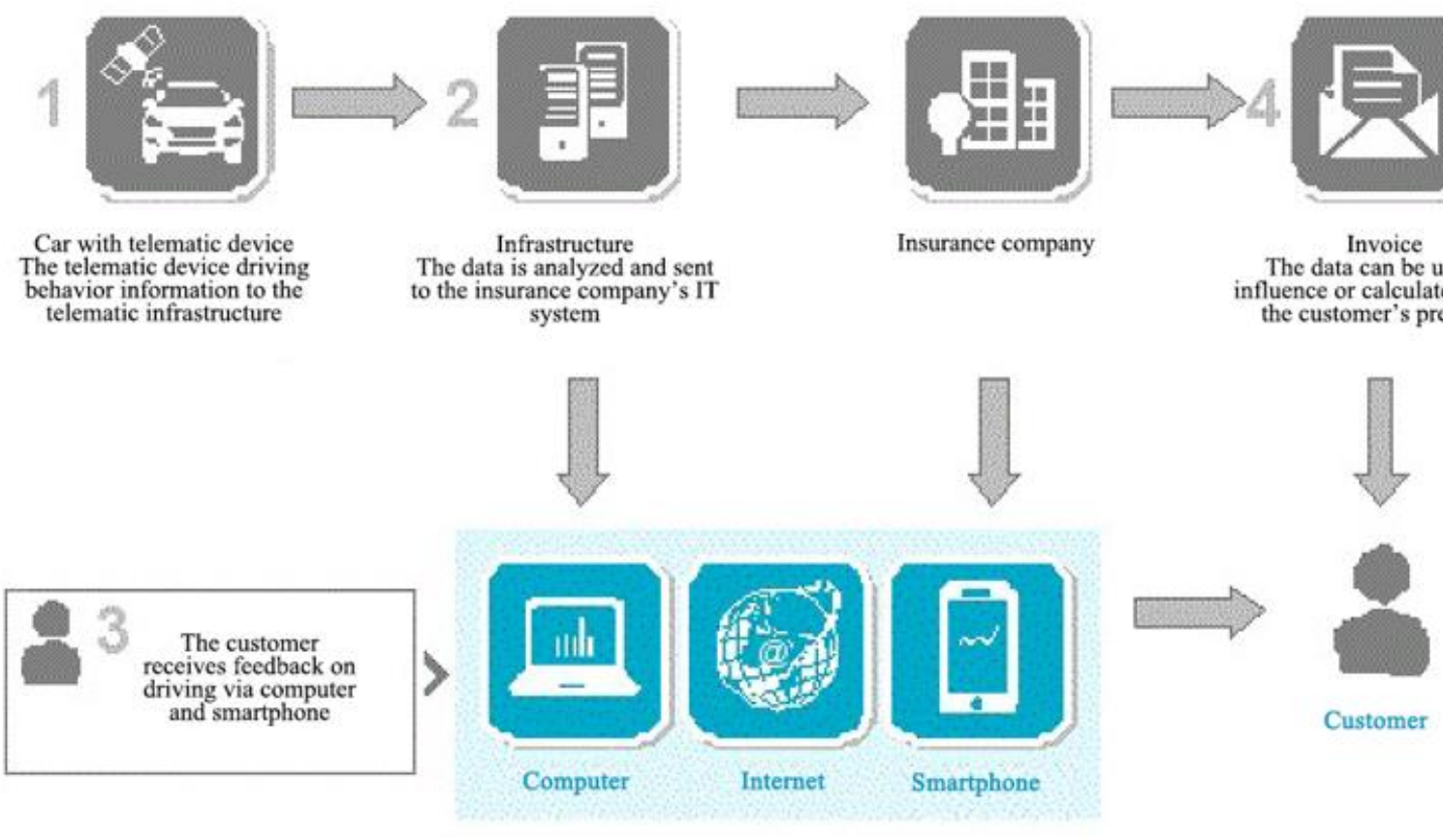

Figure 2. Telematics information usage

One of the essential focuses of this examination is to break down research in the region of driver conduct arrangements so as to address road safety issues $[19,20]$. This is accomplished through the recognizable proof and comprehension of the connection between driver conduct and road safety, and the order of drivers utilizing their desire to chance [21]. The connection between the driver and the vehicle control, and the affectability of the driver to complex driving conditions or circumstances (e.g., climate, traffic) are major contributing variables towards road accidents [22].

Road accident association is all the more firmly identified with human judgment and basic leadership than the minor failure to control the vehicle, and in this manner, the focal point of driver conduct and basic leadership designs turned into a prominent research territory in road safety applications. To dissect the convictions and qualities that comprise the choice procedure and to assess the style of basic leadership dependent on individual propensities and identity attributes. The second methodology ended up being agent and quantifiable in applications through the characterization of drivers into predefined driving styles.

Research in the territories of driver conduct observing, route task identification, driving style acknowledgment and expectation are continually developing as the requirement for creative, quick and precise arrangements with the exceed expectations in vehicle armada and road foundation enterprises. The assemblage of information around driver conduct explore is subdivided in this examination as indicated by contrasts in application and sensor stages over a scope of fields and ventures. This survey further sorts the driver conduct application territories into main gatherings of which strategies and results are contrasted all together with improvement in the comprehension of the usage and use of driver conduct investigation.

\section{LITERATURE SURVEY}

Alcañiz et al. [1] gave a first estimation to business chance administration in the insurance agency. The creators broke down the connection between the client and the back up plan, the supposed protection relationship, and dependent on that, their decisions indicated the need to consider diverse kinds of items all the while. In that specific circumstance, the creators evaluated the likelihood of arrangement undoing and the client lifetime length by utilizing genuine approach information. Moreover, the creators likewise given some direction to focusing on business accident executives in the protection 
business.

Aseervatham et al. [2] proposed Pay as you drive Distancebased vehicle protection G-book (telematics membership administration given by Toyota Motor Corporation) with Mobile information administration that calculates insurance based on the driven distance.

Ayuso et al. [3] proposed an Autograph Insurance that depends on conventional telematics parameters with a few dimensions of accident inside 24 hour time span. Gadget associated with vehicle symptomatic port Universal sequential transport is considered in this work.

Ayuso et al. [4] proposed a Protezione Satelitare Insurance depends on customary telematics parameters GPS-based Mobile information administration which calculates the premium amount based on the satellite information.

Baecke et al. [7] proposed an Accident Recording occasions Event-information recorder Data recovered from occasion information recorder which is considered for insurance calculation.

Boucher et al. [8] proposed More Than Green Wheels Insurance depends on customary telematics parameters with a few dimensions of accident inside 24 hours time frame. Gadget associated with vehicle demonstrative port Mobile information administration

Insurance agencies store approach related data amid arrangement inception and guarantee settlement. In customary accident protection arrangement, premium is determined dependent on the past case sum and deterioration of the vehicle. Anyway, it doesn't foresee chance required amid the arrangement time frame. The normal case sum is a pointer of the accident for the comparing approach holder. After case settlement, insurance agencies perform compromise of the information so as to touch base at the following premium add up to be paid by approach holder. When all is said in done, premium depends on vehicle gathering or type, year of enrollment and past case sum. Anyway, this data isn't utilized for anticipating accident required amid the strategy time frame. This case settlement information is contribution to the Web server which stores this data in the arranging database. Therefore, every strategy holder is classified in to "Accident" or "No Risk" in view of the normal case sum.

\section{COMPARISON OF LOGISTIC REGRESSION WITH LINEAR AND OTHERS}

Strategic deterioration is a modified adaptation of summed up straight model and it is like direct relapse. The reliant and autonomous factors need to help linearity in straight relapse though it is loose in calculated relapse. The contingent dissemination $\mathrm{y} \mid \mathrm{x}$ or the reliant variable is a dichotomous result and Bernoulli conveyance in strategic relapse. Be that as it may, it is a Gaussian dispersion in direct relapse. Calculated reversion is utilized for expectation and arrangement. The model is worked in three stages. In initial step, Logistic regression work is utilized to process the probabilities of results or anticipated qualities which are in the range $(0,1)$.

The protection business, particularly the engine protection division, for the most part figure their premiums in view of measurable information through the assessment of variables that are accepted to affect anticipated expense of future cases. These elements incorporate among others, the kind of vehicle, the esteem and qualities of the vehicle, just as the profile of the driver (age, sexual orientation, conjugal status, driver experience, and so forth.), which don't in every case reasonably speak to every individual driver's weakness to accident. Nonetheless, driving conduct examination can help to give an increasingly precise portrayal of a person. The outcomes in [25] demonstrated that risky driving occasions are precisely recognized and given an agent score to every individual driver.

GPS vehicle following through "discovery" units is advanced by guarantors, as the data recovered from these units can be utilized by the insurance agencies to more readily assess accident. The Drive Diagnostics framework screens onroad driver conduct, figures chance and gives pertinent input utilizing information from vehicle-fixed information recorders [26]. Strategies dependent on vehicle-fixed sensor information securing are unappealing to certain individuals who consider the possibility of consistent observing prominent. Another methodology as of late adventure is conduct based protection joined with use based protection, which utilizes driver standards of conduct and driving style characterization to improve evaluation of driver accident and safeguarded chance.

\subsection{Wise vehicles systems and autonomous vehicles}

Wise vehicle innovations comprise of electronic, electromechanical and electromagnetic gadgets that are constrained by programming based control frameworks. These smart vehicle advancements are connected to vehicle security frameworks and self-assessed criticism frameworks. Best in class vehicle transport guidelines utilizing vehicle information and telematics sensors gather however much data from the ebb and flow vehicle's development and encompassing vehicles' development as could be expected, and gauge constant criticism to give arrangements and recommendations to the driver. Keen vehicles are generally outfitted with numerous sensors to empower different handling with sufficient and delegate information accumulation from different parts of the vehicle and the driver conduct.

Vehicle communication is fundamental improvement. Accordingly, Vehicular Ad hoc Networks (VANETs) started as a use of Mobile Ad hoc Networks (MANETs), which enable vehicles to speak with one another in short range vicinity. This innovation as of now tends to road security through criticism to the driver of dangerous encompassing exercises, applying driver conduct examination applications utilizing VANET innovation, and is executed. Self-ruling vehicles and insightful vehicle frameworks utilize vehicle following models for route as driver safety applications through risky after separation identification [6]. A driver help application which assesses vehicle following models and examples recorded for a driver, to give usefulness, for example, versatile journey control and forward impact cautioning.

\subsection{Artificial Neural Networks (ANN)}

An ANN is an insight framework that imitates the organic associations of the sensory system and comprise of different amazingly interconnected handling components, that take care of issues with aggregate preparing. In an ANN, signals are transmitted through the associations between hubs of the system, each relegated with a trademark and movable weight. The movable loads empower the system to be prepared and to be upgraded through a learning calculation. In a standard ANN this weight is the multiplier with which the info is acclimated to get the resultant esteem. Nonetheless, unique sorts of ANNs 
exist to address issues in different fields. An initiation work is utilized to characterize the result of the hub that is nourished further in the system. ANNs are sorted as an AI calculation on the grounds that the system approximates enactment works and improves its approximations utilizing a learning calculation. It discovers application in driver conduct arrangements and in this study an examination is performed to recognizing the explanations behind ANN using, the criticalness of ANNs, and the outcomes calculated by utilizing the ANN as learning model in these applications.

\subsection{Bayesian networks}

Bayesian Networks address the constraint of deficient information in situations where ANNs, Fuzzy logic what's more, systems, for example, the Kalman channel won't give enough expressive abilities. In [14], driving style arrangement between four driving styles (ordinary, alcoholic, neglectful, and weariness) is performed continuously by presenting a probabilistic model dependent on Bayesian systems. Relevant data with respect to the driver, the vehicle, and the earth are melded. The dynamic conduct show catches the static and the experienced parts of the driver's conduct and prompted hearty and exact conduct discovery.

\subsection{Fuzzy logic}

Another territory of extraordinary enthusiasm for driver conduct expectation and acknowledgment is the utilization of the fuzzy logic (FL) rule. Fuzzy logic speaks to logic as a level of truth or now and again numerous esteemed logic is forced rather than twofold logic known as true or false. Fuzzy sets were presented in 1965 as a class of items with a continuum of evaluations of participation. These sets are described by a participation work which designates an evaluation of enrollment to each item extending somewhere in the range of zero and one, this is to address accuracy in logic while tending to human thinking. A fuzzy interface was utilized to recognize driver exhaustion, a versatile neuro fuzzy induction framework was utilized to identify driver diversion. The explanation behind the execution of a FL framework (FLS) is because of the capacity of a FLS to at the same time translate numerical information and phonetic learning and its capacity to outline input information to a scalar element vector yield.

A characterization was made with 2 diverse relapse models by utilizing the information of 17 organizations in Group I and 24 organizations in Group II for 2017 and 2018 years. Initially, when they were arranged by considering their prosperity rates when contrasted with earlier year for 2016 and 2017 years, the organizations in the initial 20 were delegated "effective" and others as "ineffective".

\subsection{Use of block chain}

As a sort of conveyed record, a block chain can store information received from various different sources more safely and productively than a concentrated database. Moreover, certain block chains, for example, those based over the Ethereum arrange, can implement "keen contracts," which will just finish an exchange once preset criteria are met. These capacities could be precious in circumstances where numerous gatherings need to share and approve data so as to finish a business exchange at the end of the day, every errand embraced by an insurance agency.
Think about when somebody takes out an approach on a trade-in vehicle they've quite recently bought. In a perfect world, both the driver and guarantor will know the vehicle's whole history - regardless of whether it contains unique gear maker parts or conventional forms; whether it's been associated with an accident or repair from damages and much whether past proprietors normally replaced the oil.

Under a block chain-based framework, the vehicle maker, parts provider, unique vender, safety net provider and driver could all go about as hubs on the block chain. Indeed, even the individual parts that go into a vehicle could be recorded, making an unmistakably more vigorous vehicle history report than at present exists, in a configuration that is unquestionably progressively shielded from information breaks.

Makers would be boosted to take an interest in this procedure in light of the fact that, in addition to other things, it would empower them to more readily follow which explicit vehicles contain which explicit parts. This could spare them a huge number of dollars amid an item review, since they could follow and inform singular drivers who possess vehicles with defective segments, as opposed to issuing a sweeping review on a whole make and model.

Circumstances exist where a brought together database may even now bode well, or the advantages of a blockchain-based framework probably won't merit the innovative work included. Organizations shouldn't actualize blockchains into their practices basically on the grounds that the innovation exists. In its report, Cognizant spread out a few criteria for recognizing a qualified use case for blockchain innovation:

Various gatherings are included.

There is an incentive in having shared information access on a carefully designed stage.

The procedure could profit by expanded computerization.

There is an incentive in dispensing with the requirement for a confided in middle person.

The advantages of a decentralized record exceed the advantages of a focal database, for example, inertness and adaptability.

A decentralized blockchain approach is plausible.

In view of these norms, back up plans have started investigating the accompanying use cases, in which blockchain innovation could improve business forms.

Blockchain's capacity to give an unfalsifiable, single form of reality gives a strong establishment to an assortment of mechanical procedures to turn out to be quicker, more secure, progressively exact and increasingly proficient. In any case, maybe much all the more energizing is its capability to wipe out the requirement for focal middle people to confirm the exchange. This move far from the need of outsider confirmation could completely change the conventional models whereupon whole ventures as of now work, with protection being no special case.

Many clients trust that segments directly over the business' esteem chain could profit altogether by receiving blockchain arrangements. A standout amongst the most articulated models right now lies in "keen contracts". Such contracts work on a blockchain which isn't constrained by a solitary element. Or maybe, all gatherings can trust and depend on oneself executing conventions inserted in the agreement to naturally, safely and effectively implement the agreement's execution over every single counter-party included.

At present, claims information is wastefully shared inside protection associations, operators and outsiders while manual information section preparing strategies are liable to 
significant human mistakes. The brilliant contract would apparently streamline the procedure via mechanizing claims installments, and by documenting and settling claims dependent on secure data recorded on the keen contract. In that capacity, the brilliant contract would bring down costs, increment installment speeds and give another imaginative plan of action.

\section{PROPOSED METHOD}

Vehicle telematics is the innovation of sending, accepting and putting away data about vehicles utilizing data and correspondence innovation. Vehicle telematics depends on M2M (machine-to-machine) correspondence and speaks to the trading of information between remote gadgets utilizing wired and additionally remote communication organization for telemetry and remote control.

Accessibility of PC preparing and system network in vehicles and versatile terminal gadgets has prompted a blast of accessible applications and administrations for clients. A strong telematics framework needs to be designed for calculating insurance premiums for vehicles which is not equivalent for all users and the premium has to be calculated based on the vehicle and drivers information.

\section{CONCLUSION}

The discoveries of this examination infer potential calculation for insurance agencies and drivers. We have affirmed that UBI strategies may demonstrate valuable particularly on the developing markets. Also, developing markets have extraordinary potential and insurance agencies should be proactive in presenting new plans of action. The most basic part for insurance agencies is to perceive the significance of ecological factor in adjusting the individual accident and cost. Future examinations should endeavor to approve the model with bigger, progressively heterogeneous examples, which thus will permit evaluating benefits for back up plans and drivers for a bigger scale contemplate. The usage of blockchain technique for insurance premium calculation is also discussed in this manuscript. The proposed work in this work hopefully calculates the insurance premium accurately and effectively which gets varied from user to user based on several parameters.

\section{REFERENCES}

[1] Alcañiz, M., Guillen, M., Santolino, M., SánchezMoscona, D., Llatje, O., Ramón, L. (2014). Prevalence of alcohol-impaired drivers based on random breath tests in a roadside survey in Catalonia (Spain). Accident Analysis and Prevention, 65: 131-141. https://doi.org/10.1016/j.aap.2013.12.021

[2] Aseervatham, V., Lex, Ch., Spindler, M. (2016). How do unisex rating regulations affect gender differences in insurance premiums? The Geneva Papers on Risk and Insurance: Issues and Practice, 41: 128-160.

[3] Ayuso, M., Guillen, M., Alcañiz, M. (2010). The impact of traffic violations on the estimated cost of traffic accidents with victims. Accident Analysis and $\begin{array}{lll}\text { Prevention, } & \text { 42(2): }\end{array}$ https://doi.org/10.1016/j.aap.2009.10.020

[4] Ayuso, M., Guillen, M., Perez-Marin, A.M. (2014). Time and distance to first accident and driving patterns of young drivers with pay-as-you-drive insurance. Accident Analysis and Prevention, 73: 125-131. https://doi.org/10.1016/j.aap.2014.08.017

[5] Ayuso, M., Guillen, M., Perez-Marin, A.M. (2016). Telematics and gender discrimination: some usage-based evidence on whether men's risk of accidents differs from women's. Risks, 4(2): 1-10.

[6] Baecke, P., Bocca, L. (2017). The value of vehicle telematics data in insurance risk selection processes. Decision Support Systems, 98: 69-79. https://doi.org/10.1016/j.dss.2017.04.009

[7] Boucher, J.P., Denuit, M., Guillen, M. (2009). Number of accidents or number of claims? An approach with zero inflated Poisson models for panel data. Journal of Risk and Insurance, 76(4): 821-846. https://doi.org/10.1111/j.1539-6975.2009.01321.x

[8] Boucher, J.P., Guillen, M. (2009). A survey on models for panel count data with applications to insurance. RACSAM-Revista de la Real Academia de Ciencias Exactas, Fisicas y Naturales. Serie A. Matematicas, 103(2): 277-294.

[9] Boucher, J.P., Perez-Marin, A.M., Santolino, M. (2013). Pay-as-you-drive insurance: the effect of the kilometers on the risk of accident. Anales del Instituto de Actuarios Españoles, 19: 135-154.

[10] Desyllas, P., Sako, M. (2013). Profiting from business model innovation: Evidence from Pay-As-You-Drive auto insurance. Research Policy, 42(1): 101-116. https://doi.org/10.1016/j.respol.2012.05.008

[11] Vejendla, L.N., Peda Gopi, A., Kumar Ashok, N. (2018). Different techniques for hiding the text information using text steganography techniques: A survey. Ingénierie des Systèmes d'Information, 23(6): 115-125. https://doi.org/10.3166/ISI.23.6.115-125

[12] Vejendla, L.N., Bharathi, C.R. (2018). Multi-mode routing algorithm with cryptographic techniques and reduction of packet drop using $2 \mathrm{ACK}$ scheme in MANETs. Smart Intelligent Computing and Applications, 104: 649-658. https://doi.org/10.1007/978981-13-1921-1_63

[13] Vejendla, L.N., Peda Gopi, A. (2019). Avoiding interoperability and delay in healthcare monitoring system using block chain technology. Revue d'Intelligence Artificielle, 33(1): 45-48.

[14] Rejikumar, G. (2013). A pre-launch exploration of customer acceptance of usage based vehicle insurance policy. IIMB Management Review, 25(1): 3. https://doi.org/10.1016/j.iimb.2012.12.004

[15] Sheehan, B., Murphy, F., Ryan, C., Mullins, M., Liu, H.Y. (2017). Semiautonomous vehicle motor insurance: A Bayesian Network risk transfer approach. Transportation Research Part C: Emerging Technologies, 82: 124-137. https://doi.org/10.1016/j.trc.2017.06.015

[16] Alcañiz, M., Guillen, M., Santolino, M., SánchezMoscona, D., Llatje, O., Ramón, L. (2014). Prevalence of alcohol-impaired drivers based on random breath tests in a roadside survey in Catalonia (Spain). Accident Analysis and Prevention, 65: 131-141. https://doi.org/10.1016/j.aap.2013.12.021

[17] Adell, E., Várhelyi, A., Dalla Fontana, M. (2011). The effects of a driver assistance system for safe speed and 
safe distance - A real-life field study. Transportation Research Part C, 19(1): 145-155. https://doi.org/10.1016/j.trc.2010.04.006

[18] Ayuso, M., Guillen, M., Alcañiz M. (2010). The impact of traffic violations on the estimated cost of traffic accidents with victims. Accident Analysis \& Prevention 42(2):

709-717. https://doi.org/10.1016/j.aap.2009.10.020

[19] Baecke, P., Bocca, L. (2017). The value of vehicle telematics data in insurance risk selection processes. Decision Support Systems, 98: 69-79. https://doi.org/10.1016/j.dss.2017.04.009

[20] Boucher, J.P., Guillen, M. (2009). A survey on models for panel count data with applications to insurance. RACSAM - Revista de la Real Academia de Ciencias Exactas, Fisicas y Naturales. Serie A. Matematicas, 103(2): 277-294. https://doi.org/10.1007/BF03191908

[21] Boucher, J.P., Pérez-Marín, A.M., Santolino, M. (2013). Pay-as-you-drive insurance: the effect of the kilometers on the risk of accident. Anales del Instituto de Actuarios

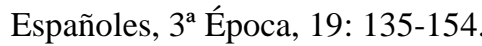

[22] Dissanayake, S., Lu, J.J. (2002). Factors influential in making an injury severity difference to older drivers involved in fixed object-passenger car crashes. Accident Analysis and Prevention, 34: 609-618. https://doi.org/10.1016/S0001-4575(01)00060-4 